\title{
Analysis of anesthesia chief resident competencies in anesthesia crisis management simulation
}

This article was published in the following Dove Press journal:

Advances in Medical Education and Practice

\section{Marilaeta Cindryani \\ I Made Gede Widnyana \\ I Gusti Ngurah Mahaalit \\ Aribawa \\ Tjokorda GA Senapathi}

Anesthesiology and Intensive Care Department, Udayana University,

Denpasar, Bali, Indonesia
Correspondence: Marilaeta Cindryani Jalan Kesehatan No.I Sanglah Denpasar Bali 80225, Indonesia

Email onkhenk@yahoo.com
Background: Anesthesia crisis management (ACM) simulation would expose anesthesiology residents and trainees to dynamic emergencies that need quick yet effective responses to gain their core strength and capabilities as anesthesiologists. Our department had already employed ACM simulation into modules and practiced in examinations. The aim is to enhance professional working ethics and human responsibility in residents, which would be accomplished in semirealistic simulation. This would be a useful tool for lecturers to evaluate current teaching methods and measure protégés in daily emergencies, which should be done better in continuous pattern. Methods: We analyzed the ACM simulation scores from resident examination using Strata SE programs. The examination consisted of four topics in which points counted for each topic ranged from 0 to 15 and then would be counted into percentage for passing grade. The required minimum passing grade for each topic was $75 \%$, in which the average score for one topic was 11.25 . Discussion: Overall average score for all subjects was 12.07 , which already achieved the $75 \%$ passing grade with a cutoff point of 11.25 . Postsurgical bleeding and cannot intubate-cannot oxygenate topics were the two bottom topics that could not achieve the $75 \%$ passing grade. Preoperative evaluation and decision making were two lowest non-technical skill scores in the examination.

Conclusion: Weakest core competencies were found in preoperative evaluation and decision making even though all subjects had already passed the minimum requirements of $75 \%$ passing grade. Postsurgical bleeding and cannot intubate-cannot oxygenate were also topics with lowest scores in core competencies. These findings would suggest for innovation and reevaluation of current teaching. Keywords: anesthesia, resident competencies, crisis management simulation

\section{Background}

Anesthesiology and intensive care residency training are characterized with mentoring and bedside teaching method involving center-based teaching hospital and its recuperating staffs. Education and training are done in a stepwise manner, starting from basic science continued with advanced practice and clinical skills with repetitive and modified techniques. ${ }^{1-4}$

Chief resident is a final stage considered with highest and optimum capabilities of anesthesia resident in accordance to a newly established anesthesiologist. Years of experience would polish the dexterity, but standard requirements and capabilities to work standard procedures are already built.

However, vigilance and emergency intuition should be owned and internalized in every daily working progress. Near misses and sentinel events still hold around $2 \%$ of all perioperative events and would ask for more than just aftermath management. Pre- 
vention started from education, and regular training is needed to prepare anesthesiologists for the worst case scenarios. ${ }^{1,2}$

Anesthesia crisis management (ACM) had already been suggested since 1990s, but still could not be implemented in all anesthesiology-based teaching institutions because of the high cost of its equipment and technology. Based on aviation training, anesthesiology residents and trainees would be exposed to dynamic emergencies that need quick yet effective responses to build intuition and deep conscience as highly skilled medical personnel. ${ }^{1-4}$

Anesthesiology and Intensive Care Department in Udayana University, Sanglah Hospital, Denpasar, Bali, had already employed ACM simulation since 2 years ago and adapted into modules and innovative study guides that are practiced in examinations for chief residents. This advanced simulation is considered to fit perfectly for chief residents in order to gain their core strength and capabilities as soonto-be anesthesiologists.

The unique and sophisticated ACM simulation method would be a useful tool for teachers and lecturers to evaluate current teaching and training methods and also to measure their protégés in daily emergency and vigilance exposures. Continuing and regular evaluation could also be analyzed to collect insight data and perspective of current advances in developing teaching department.

Our aim is to enhance professional working ethics and human responsibility in anesthesiology residents, which would be accomplished in semi-realistic simulations such as ACM. In these cases of simulation, residents vigilance would be trained without compromising real patients because they would interact with mannequins and scenarios.

\section{Introduction}

In the year of 1987-1990s, Gaba et $\mathrm{al}^{1}$ were doing a simulation research on several anesthesiologists from different years of background. They exposed the subjects into emergency situations, and the responses were evaluated and measured. They found that decision making in the operating theater was characterized with naturalistic behavior, and lots of problem occurred relatively related to inconsistent and dynamic diseases, environment, and also objectives. Short and precise timings were also included and were complicated with many different personalities in the operation theater competing to get their work done. High-risk procedures, normative and organized work ethics, and lack of positive feedback were also found. ${ }^{1-4}$

In order to bridge and enhance interpersonal communication to minimize sentinel and near miss events, Gaba et al collaborated a simulation training method based on aviation industry, which is called Anesthesia Crisis Resource Management (ACRM), consisting of comprehensive training compiled with technical and non-technical skills related to cognitive and attitude in crisis and emergency situations, which were considered relevant for daily practice. Gaba et al expected that the participants would gain several skills such as: ${ }^{1-4}$

1. Specific technical skills in various work domains according to clinical situations (for example, cardiology, orthopedics, obstetrics, surgery, and intensive care)

2. Dynamic decision-making skill, resource management skill, leadership, and applicable teamwork skills in every emergency situation.

3. Effective teamwork with different personalities and attitude.

4. Structured learning method with debriefing system and individual or team analysis of unwanted incidents.

Based on an in-depth analysis of the performance of humans exposed to emergency situations, specifically in aviation industry, human factors have been found to still contribute more than equipment failure in serious accidents. Suboptimum human performance was caused not by lack of knowledge but by lack of communication, leadership, vigilance, decision making, and teamwork. These components are called the non-technical skills that could be defined also as cognitive, social, and personal skills that act as adjunctive in technical skills to contribute in safer and much more efficient work performance. These non-technical skills were getting much more attention and also included in the ACRM simulation method developed by Gaba et al. Many non-technical skills were found, but only four of them were included and considered important in anesthesia practice, which were task management, teamwork, situation awareness, and decision making. The non-technical skills are also naturally related to ACM based on its observational technique to evaluate their valuable components, which obviously could be accomplished by the simulation method as seen in ACM.

Simulation method, in spite of its high cost, is still considered as an integral education method embedded in a specific medical course for those who work in acute and urgent situations. Simulation would help participants to be exposed to real-life emergencies, develop skills, without risking others, and also gain positive feedback from experienced instructors. Frequent exposures are proven to effectively enhance confidence and performance in real-life 
Table I Average ACM simulation scores per topic

\begin{tabular}{|c|c|c|c|c|c|}
\hline $\begin{array}{l}\text { Subjects } \\
(n=10)\end{array}$ & $\begin{array}{l}\text { Average } \\
\text { per subject }\end{array}$ & $\begin{array}{l}\text { Septic } \\
\text { shock topic }\end{array}$ & $\begin{array}{l}\text { Postsurgical } \\
\text { bleeding topic }\end{array}$ & $\begin{array}{l}\text { Foreign body } \\
\text { aspiration topic }\end{array}$ & CICO topic \\
\hline $\mathrm{DE}$ & 13.925 & 15 & 12.7 & 15 & 13 \\
\hline DA & 13.7 & 14.6 & 12.7 & 15 & 12.5 \\
\hline SW & 10.875 & 12.7 & 7.2 & 12.6 & 11 \\
\hline DO & 11.575 & 12.7 & 10.1 & 11.8 & 11.7 \\
\hline $\mathrm{AL}$ & 12.675 & 12.7 & 13 & 14.5 & 10.5 \\
\hline$A R$ & 12.1 & 14.2 & 8.4 & 15 & 10.8 \\
\hline RU & 10.8 & 12.8 & 8.3 & 13.3 & 8.8 \\
\hline WL & 11.95 & 11.8 & 10.8 & 14 & 11.2 \\
\hline KO & 10.19 & 11.8 & 9.7 & 10.96 & 8.3 \\
\hline AG & 12.875 & 14.6 & 13.6 & 14 & 9.3 \\
\hline Average in total & 12.07 & 13.29 & 10.65 & 13.62 & $10.7 \mid$ \\
\hline
\end{tabular}

Abbreviations: $\mathrm{ACM}$, anesthesia crisis management; $\mathrm{ClCO}$, cannot intubate-cannot oxygenate.

situations and also an exhilarating experience. Teamwork would also be built, and interpersonal skills are also developed gradually. ${ }^{1,7,8}$

\section{Methods}

Our eligible ten chief residents were examined through ACM simulation-based Objective Structured Clinical Examination (OSCE) ${ }^{10}$ The examination consisted of four simulation topics that are septic shock, postsurgical bleeding, foreign body aspiration, and cannot intubate-cannot oxygenate (CICO) topic. Points counted for each topic ranged from 0 to $15(0$ : lowest score; 15: maximum score) and then would be counted into percentage for passing grade. Required minimum passing grade for each topic was $75 \%$, in which the average score for one topic was 11.25.

ACM simulation scores from residents' examination were collected and analyzed using Strata SE programs. All the eligible subjects were counted and taken as subjects in this retrospective observational analysis. The Anesthesia NonTechnical Skill (ANTS) components that would be defined as core competencies were calculated and also analyzed among the subjects.

\section{Discussion}

\section{Average ACM simulation scores}

Based on the analysis results, the overall average score for all subjects was 12.07 (minimum score was 0 , and maximum score was 15 ), which already achieved the $75 \%$ passing grade with a cutoff point of 11.25. Of the ten subjects, seven of them had already passed and only for three subjects the ACM average scores were lower than 11.25. As shown in Table 1, the average ACM simulation score per topic was 13.29 for septic shock, 10.65 for postsurgical bleeding, 13.62 for foreign body aspiration, and 10.71 for CICO topic. Postsurgical

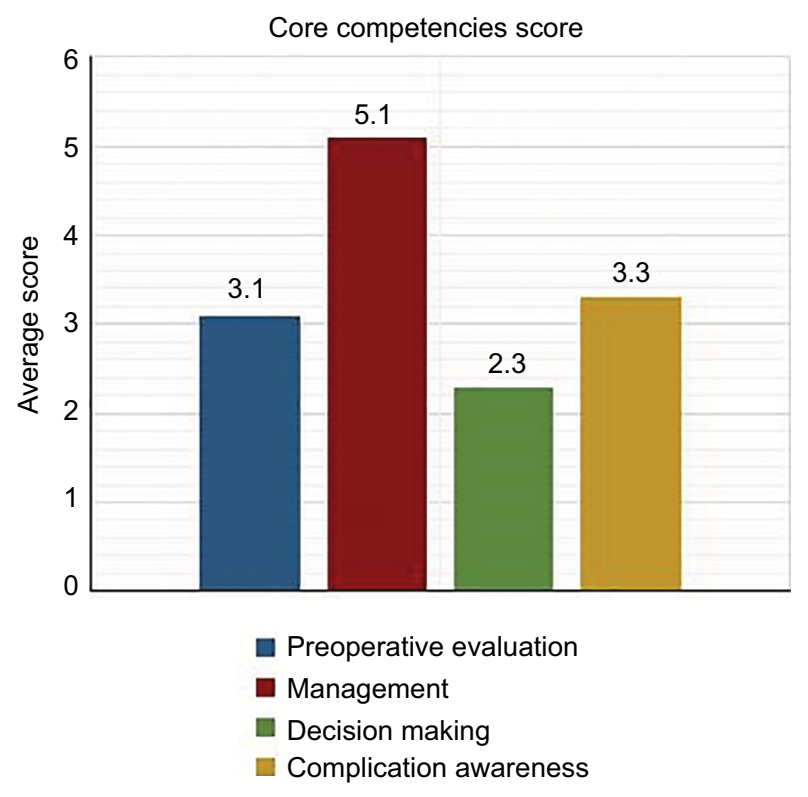

Figure I Core competencies score in ACM simulation.

Abbreviation: ACM, anesthesia crisis management.

bleeding and CICO topics were the two bottom topics that could not achieve the $75 \%$ passing grade, with only three subjects surpassed.

\section{Chief residents' core competencies evaluation}

Besides technical skills, our ACM simulation also includes non-technical skill evaluation, in which the following were considered as core competencies: preoperative evaluation, decision-making, management, and complication awareness. Our subjects were examined and analyzed on their performances in each simulation topic.

Based on the core competencies score diagram in Figure 1, preoperative evaluation and decision-making competencies 
were the two topics with lowest scores in the ACM simulation examination. Technical skills yielded in management were not the lowest core to be concerned of, yet the non-technical skills in preoperative evaluation and decision making need to be reminded and continuously considered for subjects. Further analysis in each core competency would be explained in Tables 2-6.

A 2006 research by Savoldelli et $\mathrm{al}^{5}$ had employed the ANTS behavioral marker system to assess anesthesiologists' non-technical skills. This scoring system is hierarchical and consists of four main categories of task management, teamwork, situation awareness, and decision making. A four-point scale is used to rate the performance of the subjects (Table 2).

This study had embedded the ANTS components, categories, and assessments in the evaluation and outlined them in the following four competencies that are similar to those ANTS categories.

\section{ACM simulation scores based on preoperative evaluation competency}

Results in Table 3 show that lowest ACM simulation scores based on preoperative evaluation core are in postsurgical bleeding (2.4 [60\% compared with maximum points]) and CICO (2.7 [67.5\% compared with maximum points]) topics in which deep analytical process and thorough history-taking ability should take place before proper resuscitation and airway management would be taken.

\section{ACM simulation scores based on decision-making competency}

Table 4 shows that based on decision-making competency, the lowest average score is in CICO topic (1.91 [63.67\% compared with maximum points]), ironically the most emergency situation in which quick, effective, and accurate decision making is required. The average score did not pass the $75 \%$ passing grade that would need direct attention to enhance and upgrade.

\section{ACM simulation scores based on management competency}

In the management competency, results in Table 5 show that postsurgical bleeding topic holds the lowest score in management competency (5.57 [69.6\% compared with maximum points]). Surgery and consecutive bleeding are daily practice for an anesthesiologist; however, the results were contradictive in which subjects could not pass the $75 \%$ passing grade of postsurgical bleeding topic management.
Table 2 The Anesthesia Non-Technical Skill system categories

\begin{tabular}{|l|l|}
\hline Categories & Elements \\
\hline Task management & Planning and preparing \\
& $\begin{array}{l}\text { Prioritizing } \\
\text { Providing and maintaining standards } \\
\text { Identifying and utilizing resources }\end{array}$ \\
\hline Teamwork & $\begin{array}{l}\text { Coordinating activities with team } \\
\text { members } \\
\text { Exchanging information } \\
\text { Using authority and assertiveness } \\
\text { Assessing capabilities } \\
\text { Supporting others }\end{array}$ \\
\hline Situation awareness & $\begin{array}{l}\text { Gathering information } \\
\text { Recognizing and understanding } \\
\text { Anticipating }\end{array}$ \\
\hline Decision making & Identifying options \\
Balancing risks and selecting options \\
Reevaluating
\end{tabular}

Further analysis is required to enlighten this problem and discuss ways to recuperate.

\section{ACM simulation scores based on complication awareness competency}

Different than other competencies, the complication awareness competency was specifically evaluated for septic shock and CICO topics only. Table 6 shows that the lowest average score in complication awareness is in CICO topic (1.3 [65\% compared with maximum points]). This topic demanded vigilance to be prepared for any possibilities and worst case scenarios. Score below $75 \%$ passing grade would be a sign for more assistance, discussion, and debriefing.

Previous studies conducted in aviation show that a higher fidelity of simulation does not always lead to better performance. But in anesthesiology, the effects of simulator training on job performance are more difficult to demonstrate because of the diversity of the situations, and the best use of different types of simulators for training has not been established. Nyssen et $\mathrm{al}^{8}$ have found that simulators can contribute significantly to the improvement of performance. On the other hand, it also raised questions of whether simulators could be used to assess performance because of simulated situations always a simplification of naturalistic situations of diagnosis, retention of guidelines, and technical skills, which would be different than anesthesiologist experiences in handling crisis with a wider perspective.

Another study by Yee et $\mathrm{al}^{9}$ also concluded that single simulation session would improve the non-technical skills of 
Table 3 The ACM simulation scores based on preoperative evaluation competency

\begin{tabular}{|l|l|l|l|l|l|}
\hline $\begin{array}{l}\text { Subjects } \\
(\mathbf{n}=\mathbf{1 0})\end{array}$ & $\begin{array}{l}\text { Average } \\
\text { per subject }\end{array}$ & $\begin{array}{l}\text { Shock } \\
\text { septic topic }\end{array}$ & $\begin{array}{l}\text { Postsurgical } \\
\text { bleeding topic }\end{array}$ & $\begin{array}{l}\text { Foreign body } \\
\text { aspiration topic }\end{array}$ & $\begin{array}{l}\text { CICO topic } \\
\text { DE }\end{array}$ \\
DA & 3.45 & 2 & 2.8 & 6 & 3 \\
SW & 3.75 & 2 & 4 & 6 & 3 \\
DO & 2 & 1.6 & 0.8 & 3.6 & 2 \\
AL & 3.15 & 2 & 2.8 & 4.8 & 3 \\
AR & 3.55 & 2 & 3.2 & 6 & 3 \\
RU & 3.125 & 2 & 2 & 6 & 2.5 \\
WL & 2.525 & 2 & 0.8 & 4.8 & 2.5 \\
KO & 3.675 & 2 & 3.2 & 6 & 3.5 \\
AG & 2 & 1.2 & 1.2 & 3.6 & 2 \\
\hline Average in total & 3.42 & 2 & 3.2 & 6 & 2.5 \\
\hline
\end{tabular}

Note: max: maximum points could be achieved.

Abbreviations: ACM, anesthesia crisis management; $\mathrm{CICO}$, cannot intubate-cannot oxygenate.

Table 4 The ACM simulation scores based on decision-making competency

\begin{tabular}{|l|l|l|l|l|l|}
\hline $\begin{array}{l}\text { Subjects } \\
(\mathbf{n}=\mathbf{1 0})\end{array}$ & $\begin{array}{l}\text { Average per } \\
\text { subject }\end{array}$ & $\begin{array}{l}\text { Septic } \\
\text { shock topic }\end{array}$ & $\begin{array}{l}\text { Postsurgical } \\
\text { bleeding topic }\end{array}$ & $\begin{array}{l}\text { Foreign body } \\
\text { aspiration topic }\end{array}$ & \begin{tabular}{l} 
CICO topic \\
\hline DE
\end{tabular} \\
DA & 2.5 & 2 & 3 & 3 & 2 \\
SW & 2.5 & 2 & 3 & 3 & 2 \\
DO & 2.35 & 2 & 2.4 & 3 & 2 \\
AL & 2.95 & 2 & 2.7 & 1.5 & 2 \\
AR & 2.35 & 2 & 2.4 & 3 & 2 \\
RU & 2.32 & 2 & 1.8 & 3 & 3 \\
WL & 2 & 1.3 & 2.4 & 2 & 2.5 \\
KO & 2.08 & 1.3 & 3 & 3 & 1.3 \\
AG & 2.32 & 2 & 3 & 2 & 2 \\
\hline Average in total & 2.25 & 2 & 3 & 2.65 (max: 3$)$ \\
\hline
\end{tabular}

Note: max: maximum points could be achieved.

Abbreviations: ACM, anesthesia crisis management; $\mathrm{ClCO}$, cannot intubate-cannot oxygenate.

Table 5 The ACM simulation scores based on management competency

\begin{tabular}{|l|l|l|l|l|l|}
\hline Subjects $(\mathbf{n}=\mathbf{1 0})$ & Average per subject & Septic shock topic & $\begin{array}{l}\text { Postsurgical bleeding } \\
\text { topic }\end{array}$ & $\begin{array}{l}\text { Foreign body aspiration } \\
\text { topic }\end{array}$ & CICO topic \\
\hline DE & 5.97 & 5 & 6.9 & 6 & 6 \\
DA & 5.67 & 5 & 5.7 & 6 & 6 \\
SW & 5.05 & 4.2 & 4 & 6 & 6 \\
DO & 4.9 & 3.8 & 4.6 & 5.5 & 5.7 \\
AL & 5.275 & 4.2 & 7.4 & 5.5 & 4 \\
AR & 4.775 & 4.2 & 4.6 & 6 & 4.3 \\
RU & 4.7 & 4.2 & 5.1 & 5.5 & 4 \\
WL & 4.875 & 4.2 & 4.6 & 6 & 4.7 \\
KO & 4.59 & 4.6 & 5.4 & 4.36 & 4 \\
AG & 5.325 & 4.6 & 7.4 & 6 & 3.3 \\
\hline Average in total & 5.11 (max: 6.25$)$ & $4.4(\max : 5)$ & 5.57 (max: 8$)$ & 5.69 (max: 6$)$ & 4.8 (max: 6$)$ \\
\hline
\end{tabular}

Note: max: maximum points could be achieved.

Abbreviations: ACM, anesthesia crisis management; $\mathrm{ClCO}$, cannot intubate-cannot oxygenate.

residents. Even the study admits several limitations such as lack of control group, less familiar technology orientation, and also difficulties of creating scenarios of challenging cases, and experts suggested further improvement in non- technical skills because the subjects did not achieve the maximum score.

As mentioned earlier, Gaba et $\mathrm{al}^{11}$ as the pioneer of simulation in anesthesiology had suggested to evaluate anesthesiologist 
Table 6 The ACM simulation scores based on complication awareness competency

\begin{tabular}{|l|l|l|l|}
\hline Subjects $(\mathbf{n}=\mathbf{1 0})$ & Average per subject & Septic shock topic & CICO topic \\
\hline DE & 4 & 6 & 2 \\
DA & 3.5 & 5.6 & 1.5 \\
SW & 2.95 & 4.9 & 1 \\
DO & 2.95 & 4.9 & 1 \\
AL & 3 & 4.5 & 1.5 \\
AR & 3.75 & 6 & 1.5 \\
RU & 3.15 & 5.3 & 1 \\
WL & 2.65 & 4.3 & 1 \\
KO & 3.5 & 6 & 1 \\
AG & 3.75 & 6 & 1.5 \\
\hline Average in total & $3.32(\max : 4)$ & 5.35 (max: 6) & $1.3(\max : 2)$ \\
\hline
\end{tabular}

Note: max: maximum points could be achieved.

Abbreviations: ACM, anesthesia crisis management; $\mathrm{ClCO}$, cannot intubate-cannot oxygenate.

performance during crisis using both technical and behavioral aspects such as communication, leadership, and interpersonal conflict, which are already reported as the most critical factors associated with human error incidents. This study had tried to take the behavioral aspects into account and evaluate the core competencies related to anesthesiologist technical skills.

\section{Limitations}

Our research limitations are sample size and simplification of simulated evaluation, but we believe that much more appropriate measures and collecting more data on human performance from our field in other teaching departments in Indonesia would help to develop better understanding and finally would be better simulations to meet specific requirements for anesthesiologist training.

\section{Conclusion}

Interesting results were found in the retrospective analysis of anesthesia chief resident competencies in 2016 ACM simulation. Weakest core competencies related to ANTS were preoperative evaluation and decision making described in the abovementioned tables and figure, even though all subjects had already passed the minimum requirements of $75 \%$ passing grade. Postsurgical bleeding and $\mathrm{CICO}$ were also topics with lowest scores in core competencies. These findings were perplexed because those cases were regular cases that would be found in daily practice.

These unique findings would help researchers and lecturers especially in our department to innovate and reevaluate current teaching and training methods adjusted with latest evidence-based technologies.

The ACM simulation method that has already been employed by our department is a giant step to build a highly respective education project in Bali and also support availability and distribution of skilled anesthesiologists in all around Indonesia. Further development and socialization would be needed in many adjoined teaching centers.

Finally, ANTS was considered to be highly significant and also discovered in this analysis of anesthesia chief resident competencies. Technical skills based on knowledge only are not sufficient to ensure patient safety. Evaluation and decision making were also very important to be built and trained to prepare residents in handling real-life emergency situations.

\section{Disclosure}

The authors report no conflicts of interest in this work.

\section{References}

1. Gaba DM. The future vision of simulation in health care. Qual Saf Health Care. 2004;13(Suppl 1):i2-i10.

2. Bracco D, Videlier E, Ramadori F. Anesthesia crisis resource management. Anesthesiology Rounds. 2009;8(4).

3. Fanning RM, Gaba DM. The role of debriefing in simulation-based learning. Simul Healthc. 2007;2(2):115-125.

4. Rall M, Dieckmann P. Crisis resource management to improve patient safety. Poster presented at: Euroanesthesia; May 28-31, 2005. Vienna, Austria.

5. Savoldelli GL, Naik VN, Park J, Joo HS, Chow R, Hamstra SJ. Value of debriefing during simulated crisis management: oral versus videoassisted oral feedback. Anesthesiology. 2006;105(2):279-285.

6. Flin R, Patey R, Glavin R, Maran N. Anaesthetists' non-technical skills. Br J Anaesth. 2010;105(1):38-44.

7. Fletcher G, Flin R, Mcgeorge P, Glavin R, Maran N, Patey R. Anaesthetists' Non-Technical Skills (ANTS): evaluation of a behavioural marker system. Br J Anaesth. 2003;90(5):580-588.

8. Nyssen AS, Larbuisson R, Janssens M, Pendeville P, Mayné A. A comparison of the training value of two types of anesthesia simulators: computer screen-based and mannequin-based simulators. Anesth Analg. 2002;94(6):1560-1565.

9. Yee B, Naik VN, Joo HS, et al. Nontechnical skills in anesthesia crisis management with repeated exposure to simulation-based education. Anesthesiology. 2005;103(2):241-248.

10. Borshoff DC. The Anaesthetic Crisis Manual. Cambridge: Cambridge University Press; 2011.

11. Gaba DM, Fish KJ, Howard SK, Burden A. Crisis Management in Anesthesiology. USA: Elsevier Saunders; 2015. 
Advances in Medical Education and Practice

Dovepress

\section{Publish your work in this journal}

Advances in Medical Education and Practice is an international, peerreviewed, open access journal that aims to present and publish research on Medical Education covering medical, dental, nursing and allied health care professional education. The journal covers undergraduate education, postgraduate training and continuing medical education including emerging trends and innovative models linking education, research, and health care services. The manuscript management system is completely online and includes a very quick and fair peer-review system. Visit http://www.dovepress.com/testimonials.php to read real quotes from published authors.

Submit your manuscript here: http://www.dovepress.com/advances-in-medical-education-and-practice-journal 